\title{
APPLICATION HYBRID ECO CAMPUS VEHICLE BASED ON SOLAR POWER
}

Solly Aryza Lubis, Eko Hariyanto, Hermansyah, Suherman, Moch. Iswan Perangin-angin, Kana

Saputra S., Debi Yandra Niska, Sri Wahyuni, Darmeli Nasution, M. Iqbal

${ }^{1}$ Universitas Pembangunan Panca Budi Medan, North sumatera, gatot subroto street km 4,5 Medan

sollyaryzalubis@gmail.com

\begin{abstract}
In Indonesia, Smart Hybrid Vehicle is an Important issue for vehicle in college. This paper presents a charging process for electric scooter in parking lot areas University Pembangunan PancaBudi. It allows us to evaluate a broad range of Plug-in Smart Hybrid Electric Vehicles (PSHEVs) and Plug-in Electric Vehicles (PEVs) charging scenarios and stochastic models of the power that is the demand by PEVs in the parking garage, and the output power of the PV panel are present. To impact of the PSHEVs' charging on the utility grid, a fuzzy logic power-flow controller was designed. The charging with solar cell helps to reduce emissions from the power grid but increases the cost of charging. Moreover, it offers more flexibility to prepare for the emergence of new technologies (e.g., Vehicle-to-Grid, Vehicle-to-Building, and Smart Charging), which will become a reality shortly. The system structure and the developed PHEV smart charging algorithm are described. Moreover, a comparison between the impact of the charging process of the PHEVs on the grid with and without the developed smart charging technique is presented and analyzed.
\end{abstract}

Keywords: Smart Vehicle, Vehicle Application, plug-in hybrid electric vehicles (PHEVs), solar energy vehicles (HEVs), which integrate ICE or another

\section{INTRODUCTION}

In this time Gasoline- and diesel-powered Internal Combustion Engine (ICE) vehicles ended up dominating transportation in the 20th century. However, concerns about the environmental impacts of ICE vehicles sparked a PEV renaissance at the end of the 20th century.

In the past few years, smart hybrid vehicle, which is regarded as one of typical IOT applications, has been paid enormous attention to by multitudinous international and domestic research institutions.

First, advances in electric-drive technologies enabled commercialization of hybrid electric type of propulsion source with batteries,

regenerative braking, and an electric motor to boost fuel economy. Continued technological advances have spawned PHEVs, which integrate small ICEs (or other types of propulsion sources) and large, grid-chargeable batteries that enable 10- to 40-mile all electric driving ranges, PLUG-IN hybrid electric vehicles (PHEVs) are gaining popularity due to several reasons, i.e., they are convenient, visually appealing, quiet, and produce less pollution in the environment. PHEVs have the potential to reduce fossil energy consumption and greenhouse gas emissions, and they increase the penetration. 
An intelligent method for scheduling the use of available energy-storage capacity from PHEVs is proposed. The batteries in these PHEVs can either provide power to the grid or take power from the grid to charge the batteries on the vehicles. However, the detail about the energy dispatch during charging and the $\mathrm{V} 2 \mathrm{G}$ process is not given.

Moreover, the SOCs of the PHEV's batteries are not considered during the process of sustainable energy sources, such as solar energy and wind energy, into our daily lives [1]-[3]. Furthermore, most personal vehicles in the North Sumatera are parked more than $95 \%$ of the day and generally follow the same daily schedule [4].

However, there is a need to address the potential problems caused by the emergence of PHEVs/PEVs charging. If properly managed, plugin vehicles could be charged during low demand periods of the grid which minimizes the strain on the grid and obviating major generation and transmission infrastructure additions. Charging PEV requires electric vehicle supply equipment (EVSE). EVs must be charged regularly, and charging PHEVs regularly will minimize the amount of gasoline they consume. The aggregate load in a public charging facility (e.g., public parking lot) needs to be managed carefully in order to avoid interruptions when several thousand PHEVs/PEVs are introduced into the system over a short period of time (e.g., during the early morning hours when people arrive at work). A large number of PHEVs/PEVs connected to the grid simultaneously may pose a huge threat to the quality and stability of the overall power system. The effective communication technologies are critical to the successful rollout of EVs. Thus, a reliable design has been in a college area Universitas Pembangunan Pancabudi Medan, Lowcost and effective communications with sufficient bandwidth is needed to pass needed information between PHEVs/PEVs and the controllers to perform effectively the charging and discharging. Therefore, the authors have developed a digital test bed for a large-scale PHEV/PEV enabled parking lot that integrates both an energy management module and a communications module. Fig. 1 illustrates the block diagram of the proposed charging scheme used in the parking lot.

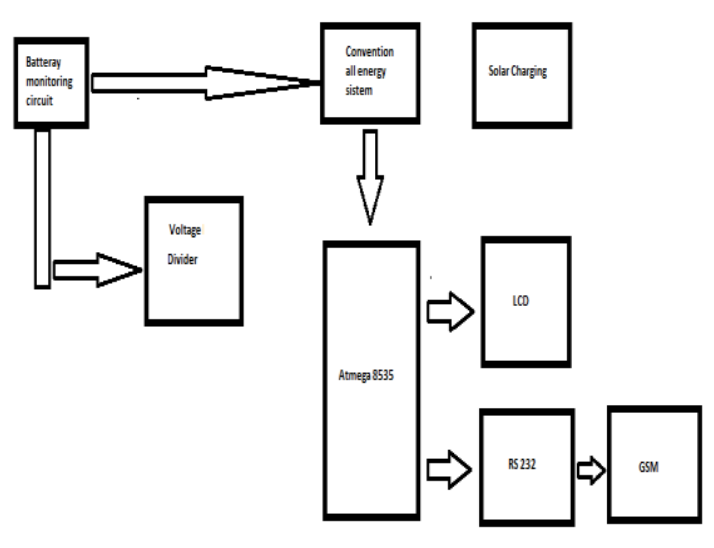

Figure 1. Block diagram of the charging scheme in the parking lot.

The charging unit consists of two types of energy used for charging of vehicles coming into the parking lot. It used the conventional means of energy as well as solar energy. In the day, the charging station charges its vehicle entering using solar power and during night hours it uses conventional energy.

The voltage divider circuit gives a reference voltage or produces a low voltage signal proportional to the voltage to be measured, i.e.,.5V required for Arduino board. The entrance to the parking area contains the controller unit for driving the vehicles after checking their battery level, entry of parking time. According to the details, the car is assigned a slot to charge. After the $100 \%$ charging level is reached, the owner of the car is intimated to park his/her vehicle in a separate parking lot, 
allowing other vehicles to charge. The remainder of this paper is organized as follows: Section II introduces the types of Power Electric Vehicle charger for exciting ride in parking space. It provides the underlying platform that will simulate the future charging system in a Smart Grid System; The proposed transportation is designed and discussed in section III. Section IV and Section V describes the energy management module and communications module. In Section VI, the authors summarize the paper and briefly introduce their future work.

\section{MODELING THE STOCHASTIC PHEVS' PARKING SYSTEM}

To manage the energy in the PsHEVs' parking garage in a real-time manner, The accuracy of the decision that is made by an algorithm is affected by the accuracy of the predictive models that are used to emulate the uncertainties in the system, i.e., the PV power in this case. Hence, we count on real data to forecast the PV output power.

The data forecasting process was base on the PV data that are collected over one year on an hourly basis for an example PV system in the Universitas Pembangunan Pancabudi, Medan. The output power data are used as the output to be forecasted, whereas the day of the year (1-365) and the hour of the day (1-24) were used as inputs. Different model evaluation indexes were used to validate the developed mathematical models. The forecasting model that is used to predict the PV output in this paper is regenerated from the model that is derived in [14] using the historical PV data described in the earlier section.

The charging unit consists of two types of energy used for charging of vehicles coming into the parking lot. It used the conventional means of energy as well as solar energy. In the day, the charging station charges its vehicle entering using solar power and during night hours it uses conventional energy. The voltage divider circuit gives a reference voltage or produces a low voltage signal proportional to the voltage to be measured i.e.,.5V required for Arduino board.

The entrance of. The remainder of this paper is organized as follows: Section II introduces the types of PEV chargers for electric vehicles in parking space. It provides the underlying platform that will simulate the future charging system in a Smart Grid System; The proposed transportation is designed and discussed in section III. Section IV and Section $\mathrm{V}$ describes the energy management module and communications module. In Section VI, the authors summarize the paper and briefly introduce their future work.

The structure of the transportation system is presented in Fig. 2 and contains: Electric Vehicles, Docking Stations and one Control Centre, as in [10].

The Electric vehicles represent the central component of the project. For evaluation purposes of this research, different types of electric rides were selected. The research team realized one scooter of original design, and purchased other vehicles: two electric bikes and one electric moped. In this way it was possible to better evaluate the own design and to compare it properly with other international implementations, from many points of view

as

motor.

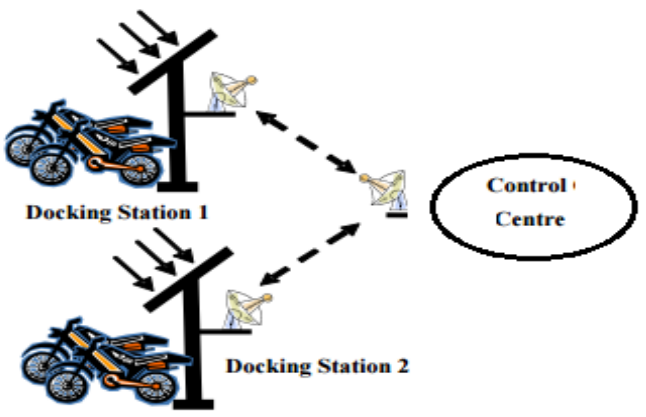

Fig 2. Transportation system structure. 
power and torque characteristics, dynamic drive organization (motor, controller, battery and auxiliaries), battery chemistry, driving facilities, auxiliary equipment (lamps, signals, and gauges, actuators, etc.), the degree of standardization and others.

The Docking stations represent the plants where the vehicles are parked and recharged between two successive rental periods. The vehicles are automatically release/received to/from authorized users, charged and verified. For charging, the station uses a second source: photovoltaic panels and the power grid. When the produced power exceeds the necessary level, the panels could supply the grid. The station monitors the professional status of each vehicle: charging, availability and health.

Each channel is controlled by a microcontroller and has a wireless communication with the Control Center. It communicates with the users by a keyboard panel and a display.

The Control Centre uses a dedicated server and wireless communications with the docking stations. It manages the users, vehicles, trips and finally could send a bill.

\section{DETAILS OF IMPLEMENTATION}

A. The Original Scooter Realized by the Research Team

The technical and financial limitations of the research team imposed to electrify an existing scooter. The Greek propulsion system (engine, transmission, tank, etc.) was replaced, keeping only the throttle and its cable, based on a dynamic model of the vehicle, as in [11].

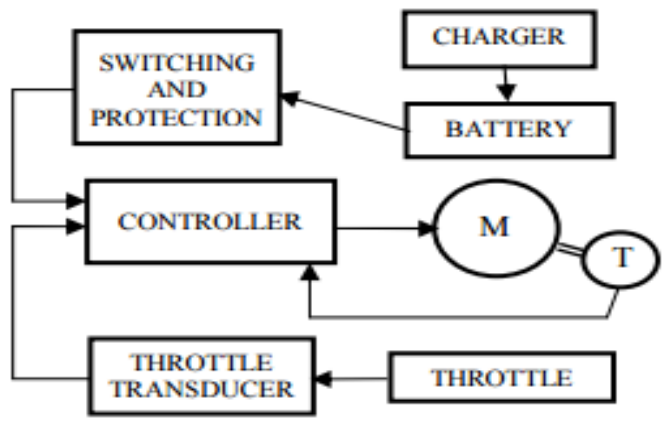

Fig 3. Electric propulsion system.

The switching block disconnects the system when the vehicle is the park and protects it in the case of over-current. It also monitors the charging status of the SLA (Sealed Lead Acid) battery. The controller connected to the in-wheel motor (machine and the incorporated Hall transducers). The driver torque command received from the original throttle (mechanical), by a cable, and a long life contactless inductive transducer.

The electric motor, developed by ICPE Bucharest, is included in the 13" rim of the rear wheel, as in Fig.3. It is a permanent magnet brushless DC motor (PM-BLDC) with outer rotor and neodymium $(\mathrm{NdFeB})$ permanent magnets. The motor has the Hall and temperature sensors included. It was designed to produce high torque, and no gear is normally necessary. However, for a superior dynamic, a planetary gear could be considered. The gear solution involves financial and technological difficulties that exceed the level of this project and has denied. The specifications of the scooter, given by the motor, are presented in Table 1.

Tabel 1. Scooter Parameter

\begin{tabular}{|c|c|c|c|}
\hline Parameter & Value & Parameter & Value \\
\hline Mass & $175 \mathrm{~kg}$ & Load & $100 \mathrm{~kg}$ \\
\hline Rated speed & $45 \mathrm{~km} / \mathrm{h}$ & Range & $60 \mathrm{~km}$ \\
\hline Rated power & $3.5 \mathrm{~kW}$ & Rated torque & $54 \mathrm{Nm}$ \\
\hline Rated voltage & $60 \mathrm{~V}$ & Charging time & $5-7 \mathrm{~h}$ \\
\hline Climbing ability & $15 \%$ & Maximum torque & $115 \mathrm{Nm}$ \\
\hline
\end{tabular}

Technosoft International realizes the controller. It is set to match the electric scooter 
motor. A three-phase inverter, DSP-controlled, with specific, short-circuit, over and under voltage, motor and drive over temperature and $\mathrm{I} 2 \mathrm{t}$ protections implemented. The battery has 5 VRLA (Valve Regulated Lead-Acid) units of 12V/24Ah produced by BSB. The battery covers the motor necessities. It corresponds to a range of at least $60 \mathrm{~km}$. The gross mass of battery is $40 \mathrm{~kg}$. The next step to improve the vehicle performance will be to change the batteries to lithium chemistry. A standard 220VAC/60VDC selected for charging so that only the standard $220 \mathrm{~V} / 50 \mathrm{~Hz}$ power supply is necessary for all vehicles.

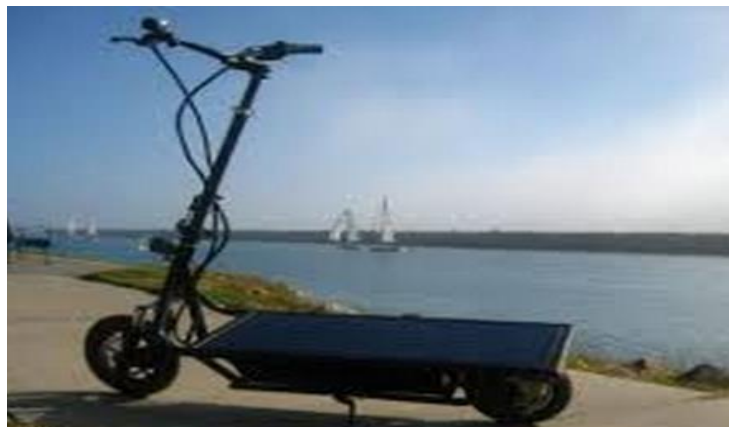

Fig 4. Vehicle Implementation

\section{ASSESSMENT CONSIDERATIONS}

The system tested in the campus of University Pembangunan Pancabudi. The selected users were ten students of the Faculty of Engineering, participants to the course "Electric and Telecommunication ". The main conclusions of this assessment are

a) Technical properties: a1) the electrified scooter respects with acceptable deviations the estimated parameters. However, it has some drawbacks as: the vehicle is heavy, especially due to the frame that is not unique, including the protective cap of the old transmission; - some solutions are not optimized, such as the throttle transducer (a complex solution with cable and inductive transducer instead of a modern Hall throttle), the heavy lead batteries which have high internal resistance, etc. a2) the moped with lead batteries has not enough power and torque to carry well the rider, especially on uphill roads, or if he has a high weight. The lead batteries have a high internal resistance, which produces an import degradation of torque at the low state of charge (SOC). The dead-weight is great Fig.5. Docking Station. Fig. 4. Vehicle implementation and if the battery is discharged, despite it has pedals, there is tough to move the moped. After $11 / 2$ years of testing, the range is almost the same, between 20 and $30 \mathrm{~km}$, depending on the rider weight and the cruising speed. Recently, a cell of one battery unit gets down. a3) the bike having an aluminum frame and a lithium battery is quite light and is convenient to handle. The electric assistance is imperative and, the physical effort is practically zero, especially in the maximum assistance level.

The torque is enough to ride a $9 \%$ slope without problems with an $80 \mathrm{~kg}$ rider. The range was excellent at the beginning, more than $30 \mathrm{~km}$, but degraded after one year to $10-20 \mathrm{~km}$. a4) the solar panels have little power. With an exquisite irradiance, at noon on a summer day, the panel controller gives $8.7 \mathrm{~A}$ at $28 \mathrm{VDC}$ ( $244 \mathrm{~W}$ of power). On the AC side this means, considering the typically declared efficiency of the inverter $(86 \%)$ a maximum available power of $210 \mathrm{~W}$. The moped needs for charging at $218 \mathrm{~V}, 0.37 \mathrm{AAC}$, and the bike $0.7 \mathrm{AAC}$, that is an apparent power of $81 \mathrm{VA}$ and 153VA respectively.

The scooter needs about 180VA. The conclusion is that the solar system can charge only one vehicle and the moped at a time, and this was the case in our application. With all vehicles charging and lower solar irradiance (during the afternoon) the power grid is necessary. a5) the docking system is simple. The electric plug, separated by the docking frame is a supplementary action which is not difficult, but the docking frame is massive and has to be redesigned. The LEDs 
light is not very high and can be seen with difficulty, especially when the sunlight is strong and directed to LEDs. The docking station display is quite small and can be seen with difficulty in the sunlight. The wireless transmission between station and Control Centre is sometimes affected by noise. a6) the graphical interface in the Control Centre should be improved. b) Exploitation considerations: b1) the security problem is critical for this system. On the one hand, the equipment is quite expensive and could be a temptation for some people. For the contrary, the material is quite sensitive and could be damaged very quickly. To overcome this problem, in this project the docking station placed at the entrance of the Faculty of Transportation and was continuously guarded by a security officer. However, after a week, some accessories were damaged and had to be replaced. Consequently, the vehicles were parked at the docking station only during the active phase of experimentation. Even more, the university campus is a recreation place for many students. Unfortunately, they play foot tennis next to the docking station, and the ball can damage the solar panels. So, it was necessary to protect the panels with a metallic net, which reduced to some extent the panel efficiency. b2) the reliability of the vehicles was also a problem. After six months, the moped controller was damaged and was replaced.

The aluminum multi-speed bikes are appropriate for individuals, but for this intensive use are sensitive and very often it was necessary to adjust or to fix something. b3) the docking station resisted well during the winter with very low temperatures (-30o C) and snow, wind and rain. b4) the software in the Control Centre and docking station was satisfactory for a first evaluation, but some functions have to be add or improved. c) Users' considerations c1) the students and staff were very attracted by this system.
The vehicles were also tested by many people, not only by authorized users. At the beginning it was curiosity and many people regarded it as an exotic novelty. After that, the majority was impressed by the electric vehicles and some decided to buy one, especially a bike. Having a more extensive experience with the exciting rides, the authorized users expressed the totally satisfaction concerning the vehicles and the transportation system. They had also suggestions, which were an important aid for the project.

\section{CONCLUSIONS}

For implementation in University Pembangunan PancaBudi North Sumatera Medan. Campus demonstrated the technical advantages of this transportation system. Students and staff also appreciated it.

\section{ACKNOWLEDGMENT}

This paper describes the results of the project "Electrocampus", supported under the program "Go Green " by the Rector of University Pembangunan Pancabudi for Education, Research, Youth, and Sport. The partners coordinated by the author were University Pembangunan PancaBudi North Sumatera Medan.

\section{REFERENCE}

[1] J. Voelcker, "How green is my plug-in?" IEEE Spectr., vol. 46, no. 3, pp. 42-58, Mar. 2009.

[2] Technology Roadmap: Electric and Plug-In Hybrid Electric Vehicles (EV/PHEV), International Energy Agency (IEA), Paris, France, 2011.

[3] A. Y. Saber and G. K. Venayagamoorthy, "Plug-in vehicles and renewable energy sources for cost and emission reductions," IEEE Trans. Ind. Electron., vol. 58, no. 4, pp. 1229-1238, Apr. 2011. [4] J. Tomic and W. Kempton, "Using fleets of electric drive vehicles for grid support,” J. Power Sources, vol. 168, no. 2, pp. 459468, Jun. 2007. 
[5] S. G. Wirasingha, N. Schofield, and A. Emadi, "Plug-in hybrid electric vehicle developments in the US: Trends, barriers, and economic feasibility," in Proc. IEEE VPPC, Sep. 3-5, 2008, pp. 1-8.

[6] S. Deilami, A. S. Masoum, P. S. Moses, and M. A. S. Masoum, "Realtime coordination of plug-in electric vehicle charging in smart grids to minimize power losses and improve voltage profile," IEEE Trans. Smart Grid, vol. 2, no. 3, pp. 456-467, Sep. 2011.

[7] A. S. Masoum, S. Deilami, P. S. Moses, M. A. S. Masoum, and A. Abu-Siada, "Smart load management of plug-in electric vehicles in distribution and residential networks with charging stations for peak shaving and loss minimisation considering voltage regulation," IET Gener., Transmiss. Distrib., vol. 5, no. 8, pp. 877-888, Aug. 2011.

[8] P. Mitra, G. K. Venayagamoorthy, and K. A. Corzine, "Smartpark as a virtual STATCOM," IEEE Trans. Smart Grid, vol. 2, no. 3, pp. 445-455, Sep. 2011. [9] C. Hutson, G. K. Venayagamoorthy, and K. A. Corzine, "Intelligent scheduling of hybrid and electric vehicle storage capacity in a parking lot for profit maximization in grid power transactions," in Proc. IEEE Energy 2030 Conf., Nov. 2008, pp. 1-8. [10] A. Mohamed, M. Elshaer, and O. Mohammed, "BiDirectional AC-DC/DC-AC converter for power sharing of hybrid AC/DC systems," in Proc. IEEE PES Gen. Meet., Detroit, MI, USA, Jul. 2011, pp. 1-8.

[11] M. Elshaer, A. Mohamed, and O. Mohammed, "Integration of sustainable energy sources into DC zonal electric distribution systems," in Proc. IEEE PES Gen. Meet., Detroit, MI, USA, Jul. 2011, pp. 1-7.

[12] A. Mohamed, M. Elshaer, and O. Mohammed, "High-quality integration of fuel cells energy into electric grids," in Proc. 4th ISRCS, Boise, ID, USA, Aug. 9-11, 2011, pp. 89-94.

[13] A. Mohamed and O. Mohammed, "Smart optimal control of DC-DC boost converter in PV systems," in Proc. IEEE/PES T\&D-LA, Sao Paulo, Brazil, Nov. 2010, pp. 403-410.

[14] P. Bacher, H. Madsen, and H. Nielsen, "Online short-term power forecasting," Solar Energy, vol. 83, no. 10, pp. 1772-1783, Oct. 2009.

[15] E. Weisstein, "Making math world," Math. J., vol. $10,2007$.
[16] L. Cam and Lucien, "The central limit theorem around 1935," Statist. Sci., vol. 1, no. 1, pp. 78-91, 1986. 